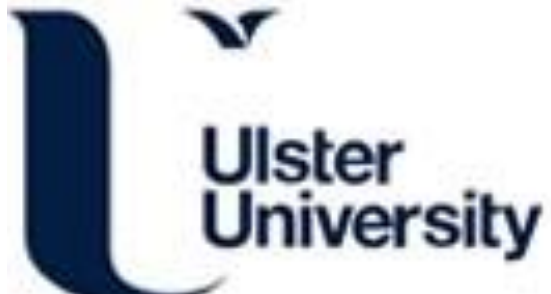

\section{Understanding which dimensions of organisational capacity support the vertical integration of disability football clubs}

Kitchin, P. J., \& Crossin, A. (2018). Understanding which dimensions of organisational capacity support the vertical integration of disability football clubs. Managing Sport and Leisure, 23(1-2), 28-47.

Link to publication record in Ulster University Research Portal

\section{Published in:}

Managing Sport and Leisure

Publication Status:

Published (in print/issue): 01/01/2018

\section{Document Version \\ Author Accepted version}

\section{General rights}

Copyright for the publications made accessible via Ulster University's Research Portal is retained by the author(s) and / or other copyright owners and it is a condition of accessing these publications that users recognise and abide by the legal requirements associated with these rights.

\section{Take down policy}

The Research Portal is Ulster University's institutional repository that provides access to Ulster's research outputs. Every effort has been made to ensure that content in the Research Portal does not infringe any person's rights, or applicable UK laws. If you discover content in the Research Portal that you believe breaches copyright or violates any law, please contact pure-support@ulster.ac.uk. 


\title{
Understanding which dimensions of organisational capacity support the vertical integration of disability football clubs
}

\author{
P. J. Kitchin ${ }^{\mathrm{a}}$ and Aaron Crossin ${ }^{\mathrm{b}}$ \\ ${ }^{a}$ School of Sport, Ulster University, Newtownabbey, Northern Ireland; ${ }^{b}$ Independent \\ Scholar, Belfast, Northern Ireland
}

Disabled people continue to face exclusion from full participation in community sports. Efforts to include disabled people in sports organisations have favoured structural solutions to make sport accessible. Our purpose was to understand which dimensions of a football club's organisational capacity assisted the vertical integration of disability football clubs. A theoretical framework combining organisational capacity and acculturation informed an exploratory and qualitative research design using semi-structured interviews. Findings indicate that the brand and the size of the organisation assisted the generation of integrative capacity. Following the acquisition of integrative capacity, two types of integration - assimilation and accommodation appeared. This study contributes to the extant literature on the vertical integration of disability sport and the management and organisation of disability football. Recommendations for policy makers and practitioners seeking to implement the vertical integration process as this study provides a theoretical and empirical perspective on how mergers can create inclusive organisations.

Keywords: Vertical integration; inclusion; disability sport; community sport; organisational capacity

Pre-publication version for Managing Sport \& Leisure, subject to edits 


\section{Preamble: The UK Social Model of disability and barriers to sport and physical activity}

In the context of sport and physical activity, disabled people ${ }^{1}$ face many barriers that exclude them from participation. An individual's circumstances create some of these barriers, such as insufficient levels of income, time and awareness (Collins \& Kay, 2003; Crawford \& Stodolska, 2009; Darcy \& Dowse, 2013; Sotiriadou \& Wicker, 2014), the type of disability, and the support needs required (Darcy \& Dowse, 2013; Darcy, Taylor \& Lock 2017). While individual circumstances play a part in creating some barriers, other barriers are created by the conscious and unconscious actions of sport and physical activity managers. These supply-side barriers are erected through inaccessible transport, facilities, programmes, outdated planning, misunderstandings in relation to the support needs of disabled participants, as well as the attitudes of other participants and the wider public (Brittain, 2004; Darcy, et al., 2017; Fitzgerald, 2012; French \& Hainsworth, 2001; Jones, 2003; Paramio-Salcines \& Kitchin, 2013; Sørensen \& Khars, 2006; Wicker \& Breuer, 2014).

How we, as researchers, practitioners and often participants ourselves view these barriers matters if we are committed to providing inclusive sport and physical activity. Our views in this regard are shaped by models of disability, which are theoretical constructs that inform how we understand disability. As the focal organisations in this paper ascribe to the UK Social Model of disability this brief preamble explains why this model frames our study.

\footnotetext{
${ }^{1}$ In this paper, we use the term disabled people in accordance language acceptable under the UK Social Model of disability (Oliver \& Barnes, 2012; Scope, 2018).
} 
Developed by disability rights activists in the United Kingdom of Great Britain and Northern Ireland (UK) - where this research is set - the UK Social Model of disability challenged the dominant 'medical model of disability' (and the medical model's view that that disability is an individual issue). It did so by pressing the political argument that the attitudinal and physical barriers disabled people face are erected by society in order to oppress them (Bundon \& Smith, 2018; Oliver \& Barnes, 2012; Townsend, Smith and Cushion, 2017). Sport and physical activity policy makers and practitioners adhering to a UK Social Model view should attempt to dismantle these supply-side barriers.

In the United Kingdom, the major strength of the UK Social Model is that it has supported disabled people to collectively challenge barriers through activism (Shakespeare, 2006a). Despite this strength, the UK social model has two important limitations. The first is ignoring the lived experience of the individual. This personal experience is often overlooked as the model's focus is on overthrowing societal barriers. Because of this the model is overly socialised (Shakespeare, 2006b; Terzi, 2004). Second, a focus on the structural causes of exclusion means that the relationship between the body and disability ignores impairment (Hughes \& Patterson, 1997; Terzi, 2004). Yet, even with these limitations - and the development of more progressive models (for instance the Social Relational and Human Rights approaches) - many organisations in the UK claim to adhere to the UK Social Model of disability. These organisations include disability rights advocacy groups, National Sports Organisations (NSOs) and Disability Sport Organisations (DSOs). Because of this adoption, we too use this model as our broad lens on efforts to achieve integrative capacity in disability football. 


\section{Introduction}

For many years, sport has been used to facilitate the social integration of people into society. In their White Paper on Sport, the European Commission (2007) recommends Member Nations use sport to foster social inclusion, integration and equal opportunities. Achieving these goals is a contemporary challenge for sport's policy makers and practitioners (Elling, De Knop, \& Knoppers, 2001; Hylton, 2013). In this paper we examine the 'vertical integration process' that seeks to develop inclusive sports organisations. Creating inclusive organisations benefits marginalised groups and can create more effective organisations (Cunningham, 2016; McConkey, Dowling, \& Hassan, 2014). As such, the purpose of this paper is to understand how (football) organisations acquire and develop the integrative capacity needed to undertake the vertical integration process. Specifically, we ask the following question; how do football clubs achieve the integrative capacity required to vertically integrate with a disability football club?

Integrative capacity is the ability to anticipate and assess the use of different approaches to solve organisational problems (adapted from Piso, O'Rouke, Weathers, 2016; Salazar, Lant, Fiore \& Salas, 2012). Salazar et al. (2012) argued that;

this capacity enables teams to build effective communication practices, a shared identity, and a shared conceptualisation of a problem space that helps [a team] recognize how their unique knowledge resources can be potentially combined to [achieve outcomes].” (p. 528)

Integrative capacity in this paper is explored using Hall et al.'s (2003) framework of organisational capacity. Vertical integration is defined as the transfer of the governance 
and operations of disability sport activities from a DSO to a 'mainstream'² sports organisation (adapted from Hums et al., 2003). Naturally, the possible organisational outcomes of vertical integration are more than simply inclusive or not inclusive, to offer a more nuanced position in this paper we conceptualise these outcomes through Berry's (1997) strategies of acculturation.

Currently, few have explicitly examined how organisational capacity allows disability sport clubs to overcome organisational problems. Wicker and Breuer (2014) explored organisational capacity in German sports clubs that provide disability sport and found that inclusive provision was linked to organisational size and their ability to plan strategically. While Wicker and Breuer's quantitative approach provided a national overview, they could not determine the quality of inclusion within these clubs. Our qualitative, resource-management perspective seeks to address this lacuna. The rest of this paper contains a further six sections. Next, the existing literature on the vertical integration of disability sport is reviewed, and then extended to what we know on the organisation and management of disability football in the United Kingdom. A theoretical framework that allows us to conceive integrative capacity and the extent of vertical integration is detailed in section three. Section four presents the context, method and basis of the data analysis. Following this, the findings are presented through Hall et al.'s (2003) framework before our conclusions reveals the outcomes of the vertical integration process undertaken by each club.

${ }^{2}$ The term mainstream has become synonymous with disability studies, often associated with the mainstreaming of education whereby children in 'special' schools were placed into 'mainstream' schools based on their learning abilities rather than their impairment. Barr (2011) highlights the difficulties with the term mainstream but in this paper, we use it as a reference to non-disabled social institutions, predominantly sporting that are in transition to become more integrated and inclusive. 


\section{Literature Review}

\section{The vertical integration of disability sport}

In Australia, North America and Western Europe, the governance of disability sport has traditionally been delivered by Disability Sports Organisations (DSOs) (Howe, 2007; Hums et al., 2003; Sørensen \& Khars, 2006; Thomas \& Smith, 2009). Many DSOs began their existence as pan-disability organisations ${ }^{3}$, but over-time many organisations evolved as demands for better representation for individuals with various disabilities or impairments emerged (Thomas \& Smith, 2009). While this enabled services to meet the niche needs of their users, it led to a proliferation of organisations that tried to govern disability sport (Ruffle, Ferez \& Lantz, 2014; Macbeth \& Magee, 2006). During the 1990s increasing political and social pressure was placed on sports organisations to become more efficient, effective and inclusive (Bouttet, 2016; Thomas \& Smith, 2009). An example of legislation was the 1998 Stevens Amendment to the Amateur Sports Act of 1978. To increase the inclusivity of sport this required NSOs to govern disability sport (Hums et al., 2003).

Institutional pressures like these fostered the vertical integration processes throughout disability sport (Howe, 2007; Hums, et al. 2003) ${ }^{4}$. Internationally, various design types of vertical integration have been attempted; the assimilation approach -

\footnotetext{
${ }^{3}$ Pan-disability in football refers to a range of impairment types, including Cerebral Palsy, wheel-chair users, blind and/or partially sighted, Deaf or hard of hearing, learning difficulties, amputees, powerchair and frame (Macbeth \& Magee, 2006)

${ }^{4}$ This policy is known across the United Kingdom as 'mainstreaming'. Mainstreaming is defined as 'integrating the delivery and organisation of [formalised] sporting opportunities to ensure a more coordinated and inclusive sporting system" (Kitchin \& Howe, 2014, p. $66)$.
} 
where the NSO integrate programmes for athletes within their existing services (as seen in Bouttet, 2016; Howe, 2007; Wicker \& Breuer, 2014); the parallel approach - where a pan-disability sports organisation is created and/or affiliated to the NSO (as seen in Kitchin \& Howe, 2014; Sørensen \& Khars, 2006); or the adaptation of the assimilation approach that ensures that DSO members were involved in the vertical integration process (Hums et al., 2003). These design types are more than merely structural approaches to including disabled athletes, their design impacts on how disability sport is perceived, delivered and how disabled athletes are treated (Howe, 2007; Sørensen \& Khars, 2006).

Research on these efforts to integrate disabled people into 'mainstream' sport is international, with findings arising from France (Bouttet, 2016); Canada (Howe, 2007); United States (Hums, Moorman \& Wolff, 2003); Australia (Jeanes, Spaaij, Magee, Farquharson, Gorman and Lusher, 2018; Sotiriadou \& Wicker, 2014), England (Kitchin \& Howe, 2014; Thomas \& Smith, 2009); Norway (Sørensen \& Khars, 2006); Germany (Wicker \& Breuer, 2014), and Italy (Valet, 2018). Following the implementation of these models, issues have arisen which appear consistently across the various national contexts. These issues include institutional pressures to integrate; a loss of organisational identity; the creation of an overt focus on performance outcomes, and related to this the prioritisation of the least disabled athletes. An overview of each of these issues is now provided.

Adopting the integration process at the behest of, or under pressure from, powerful, external stakeholders has produced mixed results (Bouttet, 2016; Howe, 2007; Ruffle et al., 2014; Sørensen \& Khars, 2006). For example, Howe's (2007) study into the integration of Paralympic athletes into Athletics Canada found that while structures were created to include disabled athletes, the profile of the athletes appeared 
subordinate to that of the non-disabled athletes - fostering attitudinal barriers. Howe drew upon ethnographic methods to reveal the exclusionary processes that maintained barriers preventing the equal standing of disabled athletes. Other studies have shown that institutional pressure upon DSOs has shifted their focus from grassroots opportunities to more elite outcomes. Within the 'French Handisport' movement this shift has resulted in the colonisation of certain sports organisations into homogenous organisational forms. These forms are more suitable to the desires of the International Paralympic Committee (IPC) than to the athletes they originally served (Bouttet, 2016; Ruffle et al., 2014). While these political and social pressures have encouraged vertical integration to occur, the risks to the DSO and their athletes are significant. Many DSOs have their own history and identity having served their athletes long before disability sport became a policy priority (Thomas \& Smith, 2009). Hums et al. (2003) suggests that if vertical integration leads to assimilation then both DSOs and their athletes could lose their identity or find their place in the organisation secondary to nondisabled athletes (Howe, 2007).

In favouring performance outcomes over participation opportunities, vertical integration diverts resources away from the grassroots - exacerbating supply-side barriers at this foundation level (Kitchin \& Howe, 2014; Macbeth, 2009; Sørensen \& Khars, 2006). For example, the selection processes for elite disabled athletes can erect a barrier which excludes athletes with more complex disabilities (Kitchin \& Howe, 2014; Macbeth, 2009). Sørensen and Khars (2006) claimed that disabled athletes "are included into able-bodied sport only if they can adjust to existing [able-bodied] values and practices" (p. 199) implying that the performance logic of elite sport has fostered assimilation. While they reported that overall attitudes toward disability sport had changed favourably, these barriers created an environment where; 
the best athletes with a disability survive in mainstream sport. However, those with greater needs for support and resources will not be able to adopt the practices and values of able-bodied sport and therefore have few opportunities to participate. (Sorensen \& Khars, 2006 p. 200)

To prevent this from occurring, greater efforts were needed to educate the stakeholders of sport about how their organisational practices discriminate against disabled athletes.

The application of vertical integration into disability football has not yet occurred. However, research has explored the organisation and management of disability football which provides an important contest for this study. As such, our attention now turns to this body of literature.

\section{The management of disability football}

Across the United Kingdom, the delivery of disability football takes place within a mix of settings; disability football clubs, schools, rehabilitation centres, numerous DSOs, professional football clubs, and more recently NSOs (Atherton et al., 2001; Macbeth \& Magee, 2006; Stride \& Fitzgerald, 2011). The importance of football to the lives of disabled people has been well-established (Atherton, 1999; Atherton, Turner, \& Russell, 2001; Hudson, Mrozik, White, Northend, Moore, Lister \& Rayner, 2017; Macbeth, 2009; McConkey et al, 2014; Stride \& Fitzgerald, 2011). Atherton et al., (2001) revealed the role that football provided Deaf footballers in the development of their personal and collective identities. Drawing on the work of Stewart (1993), Atherton et al. argued that football for the Deaf community was a bonding agent and provided one setting where being Deaf is celebrated. This contrasts with their experiences with the non-Deaf community in other settings. However, changes to the organisation of disability football altered both the opportunities to play the game and this ability to construct identity work. While vertical integration has encouraged DSOs and NSOs to 
work together and increased the opportunities for disabled footballers to play, some tensions remain.

Sporting tensions arose from conflict between the priority for participation opportunities versus performance focus (Macbeth, 2009). Additionally, the many DSOs and NSOs involved in developing disability football require careful coordination to avoid over-politicising the sport development process (Macbeth \& Magee, 2006). Identity tension is the risk that changing the practice of disability football - through the introduction of national talent development plans (Macbeth, 2009) and fast-tracking promising footballers (Macbeth \& Magee, 2006) - could cannibalise the identity of disabled footballers (Atherton, et al., 2001). This is similar to the risk of vertical integration marginalising a DSO's identity, as mentioned in the previous section, but at the individual level.

Macbeth (2009) linked changes in the governance of disability football with the creation of barriers that restricted the participation for certain disabled footballers. These restrictions included; a lack of promotion of playing opportunities; a shift from 5a-side football to Futsal (that many players found unfamiliar, and inadvertently favoured the least impaired athletes within a classification band), changes to the competition structure which required players to travel for long distances to play; recruitment practices that are exclusionary, and finally insufficient support for women in disability sport (Clark \& Mesch, 2018) and disability football in particular (Macbeth \& Magee, 2006; Macbeth, 2008; 2009).

\section{Theoretical Framework}

The analysis in this paper is informed by the UK Social Model of disability which provides the broad-gauge lens by which we consider the search for integrative capacity 
and the outcome of vertical integration. However, to understand how these two areas are achieved we bring together two conceptual models to provide a theoretical framework. First, to understand how integrative capacity was achieved we draw upon Hall et al.'s (2003) organisational capacity framework. Second, to explain the outcomes of the vertical integration process we use Berry's (1997) theory of acculturation to map the outcomes of the vertical integration process.

\section{Organisational Capacity}

Hall et al.'s (2003) organisational capacity framework sought to understand how nonprofit organisations marshalled their resources to achieve their mission. Their framework outlines three dimensions that comprise organisational capacity; human resources, financial resources, and structural capacity. The latter dimension contains three sub-elements, planning and development capacity, infrastructure and resource capacity and relationship and network capacity. This framework has been used extensively to examine CSOs in sport management research (most notably through Misener \& Doherty, 2009; Wicker \& Breuer, 2013) but has not, as yet been specifically applied to the management of football clubs. In this section, we introduce each dimension and examine its potential application to understanding how integrative capacity is achieved.

The first dimension is human resources capacity. Human resources capacity is the ability to deploy human capital within the organisation. Of all the dimensions "human capital is considered to be the key element that leads to the development of all other capacities" (Hall et al, 2003, p. 5). Like Hall et al. (2003) non-profit sport research has reflected and reinforced this point (Swierzy, Wicker, \& Breuer, 2017; Wicker \& Breuer, 2013). Many DSOs require volunteer staff to fulfil various strategic 
and operational roles. Hence, matching the role with a competent volunteer presents a common organisational problem in disability sport (French \& Hainsworth, 2001; Jones, 2003). Disability football in the United Kingdom relies on a largely volunteer workforce, therefore the recruitment and retention of qualified personnel is essential for providing adequate administrative capacity and playing opportunities.

To achieve their goals, non-profit organisations require a sufficient level of financial capacity to deploy their resources. Hall et al., (2003) refers to revenue streams in terms of more money and better money. More money is an increase in the financial resources a non-profit has access to, and while necessary, better money indicates finance that is obtained without obligations to a specific funder, for example donations. However, financial precarity and vulnerability is a common theme amongst non-profit sport organisations (Cordery, Sim \& Baskerville, 2013). Wicker, Feiler and Breuer (2013) found that German sports clubs that had clear and non-conflicting missions generated more diverse revenue sources. These sources decreased the organisation's financial vulnerability. For example, if an organisation can draw on multiple commercial revenue sources it reduces dependence on grants (Allison 2001). Also, revenue diversification can allow non-profits to provide a fuller range of product offerings. Indeed, Wicker and Breuer (2014) found that larger, multi-sport clubs in Germany were more likely to offer disability sport than smaller clubs because of a larger and more diverse financial base.

In addition to the breadth of revenue sources, Misener and Doherty (2009) identified that financial competencies were as important as the generation of finance itself. A note of caution however, if extra funds are allocated to attract highly competent staff, the risk of financial vulnerability can still increase. This is because increasing administration costs increases financial vulnerability if other revenue sources 
cannot increase also (Cordery et al., 2013). Nevertheless, the link between human resources and financial capacity reinforces the relationality of the dimensions in Hall et al.’s (2003) framework.

An organisation's structural capacity is comprised of a series of subcomponents; planning and development capacity, network and relationship capacity, and infrastructure and process capacity. Planning and development capacity refers to the competence to plan strategically. Chappelet (2011) states that strategic planning is central to a non-profit's continued existence. Wicker and Breuer (2014) linked size, planning capacity and the development of strategic policies that created the conditions to encourage disability sports provision. Nevertheless, Doherty, Misener, and Cuskelly (2014) urge caution that without sufficient human resources policy implementation can fail, creating further organisational problems.

Network and relationship capacity provides advantages for organisations by building up reserves of social capital. Sport management scholarship has shown that inter-organisational partnerships can provide CSOs with valuable links to resources and competencies (Thibault \& Harvey, 1997; Thibault, Frisby \& Kikulis, 1999). Connections between organisations and the development of respect, trust and openness have been found to build relationship and network capacity. For example, the partnership between the (English) Football Association and various DSOs increased disability football opportunities across the region, increasing the supply. Disability football clubs were able to avail of the Football Association's organisational competencies to reorganise competitive fixtures and invest in elite development, overcoming the lack of capacity that had previously erected barriers to greater involvement (Macbeth, 2009). 
Infrastructure and process capacity is concerned with the internal dimensions and day-to-day operations of CSOs, including their facilities, communication practices and culture. Process seeks to link organisational practice with culture. Research into the management of disability football found that procedural changes brought about by the partnership between the Football Association and the DSOs that provided disability football had consequences for those playing visually impaired football. As revealed in the above section, Magee (2008) showed how the recruitment of players to elite squads created barriers that were worse for certain disabled athletes than others. What was lacking in this example were adequate processes to ensure the needs of athletes were considered.

\section{Acculturation Theory}

Berry's (1997) acculturation theory was developed from his work on cross-cultural integration and the coming together of two cultures. Berry suggested that when social integration took place it rarely occurred between two cultures of equal power - they were either dominant (in this paper we refer to mainstream clubs) or non-dominant (the disability football clubs) groups. Actions within both dominant and non-dominant cultural groups can act to facilitate or prevent cultural plurality. Berry's model of acculturation (the culture changes that result from interaction between two groups) asks two key questions that provide us with four possible strategies. The questions are posed to the groups experiencing the process; is it considered to be of value to maintain one's identity and characteristics? Is it considered to be of value to maintain relationships with larger groups? Figure 1 outlines these questions and the strategies that occur as a result of these answers. 
Figure 1

Berry's (1997) acculturation strategies

Is it considered to be of value to

maintain one's identity and

Is it considered to be of value to maintain relationships with larger groups?

\begin{tabular}{|c|c|c|}
\cline { 2 - 3 } \multicolumn{1}{c|}{} & \multicolumn{2}{c|}{ characteristics? } \\
\hline \multirow{2}{*}{ Yes } & & No \\
\hline & Integration & Assimilation \\
\hline No & Segregation & Marginalisation \\
\hline
\end{tabular}

Source: Berry (1997)

The four acculturation strategies outlined by Berry (1997) include; assimilation - which occurs when members of the non-dominant group forgo their cultural identity to belong to the dominant group; segregation - which occurs when each group holds their original culture and avoids the other; marginalisation - which occurs when the non-dominant group's culture is lost and there are few or no relations between each group; lastly, integration - which occurs when a degree of cultural distinctiveness exists in both the dominant and non-dominant groups, yet participation is two-way following migration. For integration to be achieved however, Berry suggests that mutual accommodation is required, each cultural group must be oriented towards inclusion.

Berry's work has been used to examine the integration in disability sports into mainstream sport (Howe, 2007; Kitchin \& Howe, 2014; Sørensen \& Khars, 2006). As stated above, Sørensen and Khars (2006) found that assimilation provided the easiest 
route for the sports federations in their study to achieve integration. By physically including disabled athletes, but applying existing organisational practices, such as using the criteria used to assess elite non-disabled athletes being applied to disabled athletes, barriers are maintained, and assimilation is assured. Work by Howe (2007) on the integration of Paralympic athletes into Athletics Canada found that the process failed to fit within any of Berry's four categories. In response, Howe offered an extension; accommodation. Accommodation is another form of integration that is "somewhere between assimilation and segregation" (Howe, 2007, p. 146). Kitchin and Howe (2014) extended this concept to England and efforts to mainstream disability cricket. They too found that accommodation was occurring as there were few opportunities for staff and players of disability cricket to engage the dominant group in cultural exchanges. In this paper, we seek to take a further step linking the level of integrative capacity, established using Hall et al.'s (2003) framework with Berry's (1997) model and linking the vertical integration process to an acculturation strategy.

\section{Methodology}

\section{Context}

With research into the organisation and management of disability football still in its infancy, this section seeks to explain how the sport is delivered in Northern Ireland, where this study is set. Football in Northern Ireland is governed by the Irish Football Association (NSO). At the highest level the game is semi-professional as the region does not have the population nor the commercial market to support fully professional leagues. The Northern Irish Football League (Irish League) contains three divisions of men's football and the Women's Premiership totalling 37 clubs (including five clubs with both men's and women's teams). Prior to the initiative examined in this paper 
there were 29 separate disability football clubs (for details on numbers and services offered please see table 1). These clubs are voluntary sports clubs (VSCs) and while affiliated to the NSO they are autonomous organisations. In order of frequency these clubs provide participation opportunities for footballers with learning, physical, and/or sensory impairments.

Table 1

Disability Football Clubs in Northern Ireland

\begin{tabular}{lcc} 
Clubs catering for: & Number & $\begin{array}{c}\text { Involved in } \\
\text { 'Inclusive } \\
\text { Clubs' } \\
\text { initiative }\end{array}$ \\
& & 4 \\
\hline Learning difficulties and Physical disabilities & 15 & 1 \\
Learning difficulties & 11 & \\
Blind or partially sighted & 1 & \\
Hard of hearing or Deaf & 1 & 1 \\
Pan-disability - all inclusive & &
\end{tabular}

Source: Authors, NSO 
Since 2002, the NSO has located the responsibility for disability football in the Development Department which oversees elite, performance and grassroots disability football. As part of changes to the funding of the football development area within the NSO, the NSO sought to devolve the responsibility for grassroots disability football from themselves to the region's mainstream football clubs. The launch of the Disability Football Strategy (2016 -2020) (IFA, 2016) formalised this desire into an organisational strategy.

\section{Inclusive-Clubs Programme}

In 2015, the Inclusive-Clubs Programme (ICP) was launched to encourage mainstream clubs to merge with local disability football clubs. Michael (NSO) stated that the ICP sought to replicate the way mainstream provision occurred - where grassroots football is developed by the clubs. To enact the ICP, mainstream football clubs and some disability football clubs received a mixture of financial and intellectual support from the NSO to merge into one club. Once the merger had taken place the disability football club would cease to operate but become the disability football section for the mainstream club. As part of the programme, the part-time, casual voluntary staff associated with the disability football club would be employed by the mainstream club. Clubs were encouraged to self-fund the new disability section as the NSO funding was planned to end after three years.

At the outset of this research (January 2016) five integrated football clubs had been developed, three within the greater Belfast region (City Rovers, City Albion and Town United - all pseudonyms), one in the West of Northern Ireland (Country Athletic) and one on the North Coast of Northern Ireland (City Wanderers). Some background 
details for these organisations is presented in table 2 highlighting their differing organisational status, size, history, set-ups and members/participants.

Table 2

Participating organizations in 'Inclusive Clubs' programme

\begin{tabular}{|c|c|c|c|c|c|c|c|c|}
\hline $\begin{array}{c}\text { Organis } \\
\text { ation }\end{array}$ & $\begin{array}{l}\text { Year } \\
\text { establish } \\
\text { ed }\end{array}$ & $\begin{array}{l}\text { Level of } \\
\text { competit } \\
\text { ion }\end{array}$ & $\begin{array}{l}\text { Local } \\
\text { Profile }\end{array}$ & $\begin{array}{l}\text { Included } \\
\text { in } \\
\text { Sample }\end{array}$ & $\begin{array}{c}\text { Employ } \\
\text { ees } \\
\text { FT/PT/C } \\
\text { asual/Vo } \\
\text { luntary }\end{array}$ & $\begin{array}{l}\text { Commu } \\
\text { nity } \\
\text { Departm } \\
\text { ent }\end{array}$ & $\begin{array}{c}\text { Football } \\
\text { Academ } \\
\text { y }\end{array}$ & $\begin{array}{c}\text { Ave. } \\
\text { home- } \\
\text { match } \\
\text { Attende } \\
\text { es } \\
\end{array}$ \\
\hline $\begin{array}{l}\text { City } \\
\text { Rovers }\end{array}$ & 1882 & $\begin{array}{c}\text { Semi- } \\
\text { professi } \\
\text { onal- } \\
\text { Irish } \\
\text { League }\end{array}$ & High & Yes & $\begin{array}{c}3 / 16 / 50 / \\
150\end{array}$ & $\mathrm{Y}$ & $\mathrm{Y}$ & 1500 \\
\hline $\begin{array}{l}\text { City } \\
\text { Wander } \\
\text { ers }\end{array}$ & 1927 & $\begin{array}{c}\text { Semi- } \\
\text { professi } \\
\text { onal - } \\
\text { Irish } \\
\text { League }\end{array}$ & High & Yes & $\begin{array}{c}3 / 8 / 25 / 1 \\
00\end{array}$ & Y & Y & 900 \\
\hline $\begin{array}{l}\text { City } \\
\text { Albion. }\end{array}$ & 1928 & $\begin{array}{l}\text { Semi- } \\
\text { professi } \\
\text { onal - } \\
\text { Irish } \\
\text { League }\end{array}$ & High & No & $\begin{array}{c}2 / 16 / 20 / \\
120\end{array}$ & Y & Y & 1500 \\
\hline $\begin{array}{l}\text { Country } \\
\text { Rangers }\end{array}$ & 1985 & $\begin{array}{c}\text { Amateur } \\
\text { - Mid- } \\
\text { Ulster } \\
\text { Football } \\
\text { League }\end{array}$ & Medium & No & $\begin{array}{c}0 / 6 / 20 / 3 \\
0\end{array}$ & $\mathrm{~N}$ & $\mathrm{~N}$ & 250 \\
\hline $\begin{array}{l}\text { Town } \\
\text { United }\end{array}$ & 2007 & $\begin{array}{l}\text { Amateur } \\
\text { - local } \\
\text { junior } \\
\text { leagues }\end{array}$ & Low & Yes & $\begin{array}{c}0 / 2 / 35 / 3 \\
0\end{array}$ & $\mathrm{~N}$ & $\mathrm{~N}$ & NA \\
\hline
\end{tabular}

Source Authors.

\section{Procedure}

This research is set within the social constructivist tradition, in that knowledge that individuals gain is created through their interaction with the environment. Hence, there 
are no absolute truths and what truths exist are socially constructed. Therefore, to address our research question we adopted an exploratory, qualitative approach to data collection.

\section{Sampling}

A combination of convenience and snowball sampling was used to select the interviewees for this research project. We drew on this sampling approach as the population of five clubs was small. This approach does have limitations. Hennink, Hutter, and Bailey (2015) identified that this technique is based on using social networks that are likely to be from similar social backgrounds. To combat against this, they recommend having several different approaches for snowball recruitment. First, we contacted Michael (pseudonym), the relevant Development Manager at the NSO. He suggested two clubs who he thought would be willing to take part in the study (City Wanderers and Country Rangers), plus he offered to take part to present an NSO perspective. After contacting each the clubs, we were granted access to staff from three of the five football clubs, two within city locations (City Rovers and City Wanderers) and one Town club (Town United). City Albion and Country Rangers did not respond to our requests to be part of this study. This was understandable as the participation of ICP clubs was not compulsory and the programme was still in progress at each site.

Second, following contact with the clubs we used inclusion criteria to ensure we selected managers directly responsible for the vertical integration process. These inclusion criteria were set to include staff who had managerial responsibility for the newly found disability section of the football club and/or the disability football club, and staff who had ongoing responsibility for the management of the ICP. While our inclusion criteria provided us with informed respondents it did present a critical 
limitation of our study. Misener and Darcy (2014) have highlighted the marginalisation of disabled people's voices within disability sport research, something which we find ourselves contributing to. Within the sample there were no staff who self-reported disability or impairment. As our focus was on managers' experiences of capacity building and the vertical integration process we feel the current respondents can provide this managerial insight (details of the respondents are contained in table 3 ).

Table 3

Participants and organizations

\begin{tabular}{lc}
\hline Pseudonym & Organization \\
\hline Michael & NSO \\
Gerard & Town United \\
Margaret & Town United (disability section/disability football club) \\
John & City Rovers \\
Kieran & City Rovers (disability section/disability football club) \\
Conor & City Wanderers \\
Catherine & City Wanderers \\
Christopher & City Wanderers (disability section/disability football club)
\end{tabular}

Source:

Authors

\section{Data collection tools}

Semi-structured interviews were used to gather data. Both researchers were present during the interviews to improve the quality of data capture, while one asked questions the other recorded notes. The interviews ranged between 70 minutes and 120 minutes and verbatim transcripts were created immediately following each interview (a selection 
of interview questions is contained in table 4).

Table 4

Selected interview questions

1. Now you have merged to create a disability section, what extra responsibilities does your club now have?

2. In managing the merger how did you divide the roles and responsibilities for the development of disability football?

3. Apart from more money, could you identify one factor that would increase the capacity of your organisation to accomplish its mission?

4. The cost of participation is a common barrier for disabled people, how do you set (determine) the price you charge?

5. Where is your greatest need for volunteers? Was this the same before the merger?

a. What are your recruiting and retention practices for your volunteers?

b. Have volunteers from the disability football club been involved in the larger club's responsibilities?

c. How do you ensure your staff are trained and equipped for working with disabled athletes?

d. What additional resources have you been required to gather in order to offer this mew section?

Source: Authors

Data analysis

Our process of analysis adhered to Braun, Clarke and Weate's (2016) stepped approach to thematic analysis. First, we created a coding manual drawn from our literature search 
and our theoretical framework. These codes were tested for reliability against the transcript from Michael's interview. For the wider process of reliability testing, both researchers were informed by the UK Social Model of disability (Oliver \& Barnes, 2012; Scope, 2018). Both coders familiarised ourselves with the transcripts before performing data retrieval separately. While a priori codes dominated, opportunities remained for the emergence of themes from the data (for an example of how codes were drawn from the data please see table 5). As an example of tan emergent code was the club's brand. This brand allowed a club to increase its financial and human resource capacity. Finally, as patterns emerged between the data we checked for cross case comparisons between the different clubs. A final process of reflection attempted to mitigate for each researcher's interpretive bias by cross-checking each other's analysis. 


\section{Table 5}

An example of coding

$$
\text { Text - Catherine (City Wanderers): }
$$

Code

Concerning the value that will never stop us to be brutally

\section{Financial/Human:}

honest. It will more be the availability of coaches and to be

Growing the club is not

able to have somewhere to do it. That's what will limit how

going to be a financial issue.

far we can go. Ideally, we would like to take it out to some of

Not having the human

the outlying local areas, but you know to do that I need Conor

capacity will be an issue.

or other coaches available to do another night. Are there

secure facilities out there? We can't just take the kids to any

whole in the wall. We wouldn't do it with the mainstream

guys, and we certainly wouldn't do it with the disability guys

[Sic.]. The safety of the kids is paramount.

\section{Structural Capacity: \\ Infrastructure and process}

- the need for specialised

facilities to offer the right

level of service that would

be expected throughout the

club

Source: Authors

\section{Findings and Discussion}

Each club studied had merged to create an expanded football clubs, complete with a disability section. In the following discussion we draw on Hall et al.'s (2003) framework to examine how the club acquired or developed the integrative capacity necessary for these outcomes. 


\section{Human Resources Capacity}

Hall et al., (2003) found that most of the work in non-profit organisations was carried out by a small number of volunteers, who were often overworked. Lacking specialist staff restricts the capacity of organisations to offer quality services (French \& Hainsworth, 2001; Jones, 2003). Michael at the NSO suggested that human resources were 'stretched' for most local clubs. He opined that mainstream clubs that did not take part in the programme had been unwilling to attempt integration because they did not have the capacity to sustain this effort. Even in attempting to take on the challenge, Town United found generating sufficient human resource capacity to be challenging. All personnel were volunteers, which meant the day-to-day management of the club occurred outside normal working hours;

The secretary works in Dublin during the week, so he can do things on the weekends and help out from a distance. But he can't do facetime, we are finding it demanding in our lives and our wives are commenting more and more frequently as well as doing the day jobs and so on (Gerard, Town United).

Therefore, to add a new section, with new players and coaches placed Town United under resource pressure.

Both City Clubs were established over 80 years ago and played in the Irish League. This longevity provided formalisation, routinisation and a level of administrative professionalisation that made it easier to delegate new responsibilities to existing staff. Meanwhile, the manager of Town United suggested that his club, and its lack of formalisation made the prioritisation of other business issues inevitable:

We're trying to expand out to a child protection officer, health and safety officer and volunteer coordinator. So, it's a big list that needs to be sorted, and I'm doing that at the moment. So, there's a lot of other roles that were trying to put in place to manage the business (Gerard, Town United). 
As clubs volunteered to merge with their local disability football clubs these priorities make the decision to volunteer an interesting one for Town United. However, as Town United is younger than the City clubs, these comments reflect previous findings. It is not uncommon for smaller CSOs to lack formal systems when they require volunteers to fulfil their main administrative duties (Doherty, et al., 2014; Misener \& Doherty, 2009).

Attracting and retaining competent human resources who have a nondiscriminatory attitude towards disabled people is a resource challenge for disability sport (Jones, 2003; Sorensen \& Khars, 2006). However, in this study, two of the three clubs reported few issues finding volunteers. Managers from both City clubs felt human resource issues was less important than other capacity issues as volunteers tended to approach them. Rather than bringing in any old volunteer however, interviewees suggested that they were 'selective' (Conor, City Wanderers) of the people they recruited as working with disabled people was seen as a sensitive area. Indeed, Kieran (City Rovers) reiterated the need for specialist staff, but also referred to a 'certain type of person' who has the skills and experience of working with disabled people:

The volunteer has to be of a certain standard of person, never mind a coach. For me it would be all about the person before I would even talk about football and introduce them to kids, they have to be the right person and understand the complexities of working with people with disabilities (Kieran, City Rovers)

This perception that it takes a certain type of person to coach disabled footballers was a common theme from these two clubs. In light previous research on the barriers created by human resources, it is a positive sign to see that clubs are cautious in the selection of staff to work in disability football. Nevertheless, it was only the City Clubs that had the luxury of being selective when recruiting volunteers. Margaret, from Town United 
mentioned that her organisation struggled to retain volunteer staff after providing them with training; "we got maybe 12 through [the Level 1 Course] and not one has come down to help out. These people are certificate collectors" (Margaret, Town United). The internal capacity to retain these qualified volunteers was arguably limited because of the scale of Town United. Our findings suggest that the larger, more established clubs attracted and retained suitably qualified and knowledgable volunteers more easity than the smaller, less established Town Club.

\section{Financial Capacity}

Financial precarity is often associated with CSOs (Cordery et al., 2013). The additional administration and equipment costs of adding a disability football section placed greater strain on each club's already stretched resources. Insufficient revenue and a lack of revenue diversification places constraints on operations and limits the ability of a CSO to lower supply-side barriers. Here, the revenue sources used to fund each disability section included NSO grants, government grants, fundraising and financial crosssubsidies from the mainstream club. This presents a modest level of financial diversification. Respondents in this study argued that access to more money from the NSO (NSO grants) would have allowed their organisations to expand operations and plan for long-term sustainability. So, while some funding was available from the NSO, these funds alone could not generate the financial capacity to sustain the disability section.

In the absence of increased funds through the NSO, each of the clubs focused on obtaining government grants (the most common source of 'more money'), and fundraising (the most common source of 'better money'). Town United secured 'more money' from local government training grants to re-invest in their human resource 
capacity:

I mean this year we will invest the best part of $£ 5,000$ training from our fundraising efforts. Some of that we will get back in grants and so on, but the club is making that commitment. This weekend we have got 10 coaches who will be going through their NSO level 1 . Then there's another 10 or 11 already qualified, and there's another 4 or 5 in the next course in April/May (Gerard, Town United).

Fundraising activities and 'fun days' were the most popular method of securing 'better money'. These funds contributed to the ongoing costs of integrating the clubs:

We had a successful fundraising event recently for our disability section, we raised $£ 1667.50$, and it will pay for two teams to go to England this summer for a competition. This was a bit of fun for all involved and it takes some stress of the overall financial picture of the club. We will be planning on doing other fundraising activities in the future to help with these costs (John, City Rovers).

All respondents indicated that their organisations cross-subsidised the disability section from the mainstream club, suggesting that each was supportive of integration. This rationale for cross-subsidising was to make the provision more affordable for disabled footballers. Of the three organisations, the two City Clubs expressed the greatest desire to continue to cross-subsidise these costs. The biggest concern for Town United was they felt they invested too much money into their disability section and it was something that they had to consider going forward:

What's the plusses and minuses of having a disability section, just like any other part of the club and how big a minus are we willing to live with to fund it? That will be a decision that we will have to address as we go into budgeting and fee setting for next season (Gerard, Town United).

The cross-subsidisation of disability sport involves the reallocation of funds from one area of the sports organisation to another and has been found to assist in the 
development of disability sport in previous studies (Sørensen \& Khars, 2006; Wicker \& Breuer, 2014). We contend that this process assists vertical integration to occurr, and in this context we posit this is an essential reality of local sport development. In all, these financial capacity responses confirm previous findings from VSCs in Britain reflecting Allison's (2001) finding that “clubs are usually quite under-developed regarding their finances and operate on a very basic income and expenditure account" (Allison 2001, p. 7).

\section{Structural Capacity}

Hall et al. (2003) identified that structural capacity includes "the processes, practices, accumulated knowledge, and support structures within an organisation that help it to function" (2003, p. 37). The structural capacity dimensions that affected each club have been arranged into three themes, discussed forthwith.

\section{Planning and Development Capacity}

Wicker and Breuer (2014) found that organisations that planned ahead had experienced the fewest organisational problems and were most likely to provide disability sport opportunities. Managers at the three clubs were aware of the need to plan strategically to develop their disability sections, but all indicated that the focus was on day-to-day responsibilities and that planning was often informal. When questioned as to whether vertical integration was a club ambition prior to the ICP being launched, responses were positive. Both Kieran and Gerard indicated that developing a disability section was an area of priority for the clubs: 
I suppose we have an idea of the general direction that we want to take the club but there is nothing in black and white to suggest yes, we will follow this path or that path (Kieran, City Rovers).

It hit us a bit more rapidly than we expected. In our five-year plan, it came in year one... because locally we are recognised as doing a lot of things right (Gerard, Town United).

The latter comment is illuminating as although receptive toward the disability football club, Town United struggled to deploy the resources to achieve integrative capacity across human and structural capacities.

Each respondent was asked to reflect on their vision for their expanded clubs. City Rovers wanted to create a youth club environment for disabled people and to provide opportunities for them to develop beyond sport. The manager of City Wanderers did not want to treat their disability section as a "babysitting service" (Conor) he wanted to ensure that coaches could deliver a "decent" standard of a session and that the participants would leave having learned something new. However, planning capacity was limited by the urgency of day-to-day operations and a belief expressed by respondents that there was a lack of NSO funding to support their work.

One barrier that planning could not break down for City Wanderers however, was that of distance. Every other week, the NSO facilitated inter-club competitions in Belfast. For City Wanderers this involved a 130-mile $(200 \mathrm{~km})$ round trip. This geographic dislocation from the other clubs prioritised weekly logistical planning simply to get a team to the competition and as such impeded their efforts to plan over a longer period.

Relationship and Network Capacity 
Multiple partners, both sporting and non-sporting who recognise the needs of the community can assist to improve programmes (Misener \& Doherty, 2009; Vail, 2007). Wicker and Breuer (2014) found that disability sports clubs had a more extensive network than non-integrated mainstream clubs. In our study we found the primary partnership was the connection between the NSO and the football club mainly due to funding provided but also the NSOs role as competition organiser. Town United and City Rovers sought to develop external networks to benefit their club and their newly acquired disabled athletes. Kieran sought to leverage his club's urban networks to get his players into paid work;

I want to get involved with as many organisations as I can to help them out [participants] and to give them some work experience and potentially some routine moving forward once they finish in school (Kieran, City Rovers).

By providing support for players to gain employment Kieran felt that the regular routine would make the school-work transition easier and participate longer at the club, boosting their sustainability. Gerard at Town United reported that some networking opportunities were planned;

\footnotetext{
We're a member of the sports forum, not an overly active member I have to admit... We have a councillor who coaches for the club, and we build out from there, but I would like to do more of that and get government advice that could work well for us (Gerard, Town United)
}

However, when it came to develop this dimension of capacity his comment may reflect the tautological thoughts of many managers in sport who are preoccupied with day-today operations; 'there is a long list of things that I have to get sorted, and while important networking is at the bottom' (Gerard, Town United).

\section{Infrastructure and Process Capacity}


Insufficient internal and external communication, inadequate facilities and exclusionary practices are all barriers that can impede the development of infrastructure and process capacity. In relation to each organisation's perceived capacity to deal with a merging disability section, both City Clubs described their transition as "smooth" (Conor, City Wanderers) and "straight forward" (John, City Rovers). The manager of the disability football club merged with City Wanderers, Christopher also spoke positively of the integration between his club and the mainstream club.

The quality of organisational communication is an important aspect of infrastructure and process capacity. Effective communication throughout the organisation has ensured the efficient use of resources, yet a failure to communicate has been found to be a problem following vertical integration (Sørensen \& Khars, 2006). At Town United, Margaret believed that the quality and level of commination between them and the mainstream club was ineffective. The communication issues between the board and the manager of the disability football club were exacerbated by Margaret's assumptions that the management committee may have integrated the disability section for more opportunstic reasons (access to funds, increased profile) than for a genuine desire to offer a more complete range of services. Hence, better communication may have prevented these assumptions from forming.

Another factor that may have smoothed this transition for the City Clubs was that they possessed their own facilities. Nevertheless, the possession of facilities did not mean open access for the disability section, managers at City Wanderers explained the common logistical pressures with having six teams (senior men's, senior women's, reserve men's, third men's, a youth academy and a disability section) vying for space; 
Yes, now that issue is an issue that we have right across the board. The facilities, that's not a disabled issue, the provision of outdoor facilities here is atrocious.

(Catherine, City Wanderers)

An interesting example of how process capacity can maintain barriers was seen at Town United, who used local, communal facilities to operate their club. Gerrard said it was not just the acquisition of new space in the facility that was preventing more playing time but the process of determining the costs and benefits to the whole club of renting more space. So, the process on a cost-benefit basis limited the programme highlighting how barriers are maintained on economic reasons. This issue arising from infrastructure and process capacity has restricted the possibility of integrative capacity being realised at Town United, and Margaret - the long-time manager of the disability football club - has acted to maintain their distinctiveness;

We prefer to stay in our separate group, to be honest with you... I'm used to working with people who say there's your group, do your job and that's how I work. We feel like we are being supervised here and it's not nice (Margaret, Town United).

\section{The importance of a recognisable brand}

In this study, we reveal that the brand image and reputation proved to positively impact on each club's integrative capacity. All three mainstream clubs had provisions in place to welcome the disability football club by incorporating the new section into existing club processes. Examples of this included the adoption of shared social media accounts, and ensuring disabled athletes wore the same sporting kit as other members of the mainstream club. Both City Clubs (established Irish League clubs) said their profile helped them attract and retain volunteers, raise finance and develop partnerships. As examined above, the discernment over potential human resources was a result of their 
brands. Given the banks of human resources within each club, they each delegated responsibility to a team of volunteers to facilitate vertical integration. For the disability football clubs, the possibility of merging with one of these brands was sold as an ideal move by the NSO. In this case it allowed two such clubs to inherit the brand and status of a high-profile football club and assist the integration process.

In contrast however, Town United - an amateur non-league club, had one person carrying out the roles of several people, minimal funds, poor communications and underdeveloped relationships. Each of these factors appeared to impact on the club's ability to operate at optimum. Margaret suggested that there may not have been another other option for the NSO other than to merge her club with the Town United. Moreover, Margaret opined that if her club had merged with an established organisation, then this may have prevented some of these difficulties. This assumption that the brand or status of the club would have allowed them to overcome other resource limitations reflects previous research. Swierzy et al. (2017) found that where organisational competence attracts volunteers, who thought their involvement minimise resource limitations that many non-profit organisations face. On this basis we posit that this focus on vertical integration in sport at club level, as opposed to the NSO level most frequently examined in previous literature (Howe, 2007; Kitchin \& Howe, 2014; Ruffle et al, 2014) shows how a brand can act as a positive facilitator in gaining the integrative capacity required to achieve vertical integration.

Despite shortcomings in structural capacity, each club was able to vertically integrate with disability football club. This suggests that paramount to vertical integration occurring human and financial capacities, plus branding generate integrative capacity. Arguably sustaining the partnership then relies on structural capacity as these 
are the plans, processes and relationships that support the work over time (Thibault \& Harvey, 1997). Based on these findings the following section will reveal the integration strategy that exists within each club before providing theoretical, managerial implications.

\section{Conclusion}

This paper sought to understand which dimensions of organisational capacity support the vertical integration of disability football clubs. In this exploratory study, the larger the club and the more established the brand the more seamless the merger. As such it appears that the brand is one of sufficient profile that disability football clubs saw greater value in merging with it. By examining the ICP through Hall et al.'s (2003) framework we can see that in all three clubs integrative capacity was achieved. This was made evident by the ability of each merger to produce a disability section. However, we now draw on Berry's (1997) framework to reveal a more nuanced status on their state of vertical integration.

We posit that two of the three organisations in this study reflect assimilation, while the other suggests accommodation (Howe, 2007; Kitchin \& Howe, 2014). While the connotations of assimilation and accommodation appear negative, as seen in the previous section integrative capacity has been achieved. Both assimilation and accommodation are types of integration, but not integration where there has been a mutual exchange of values between the disability football club and the mainstream club (Berry, 1997; Howe, 2007) this is effectively what Sørensen \& Khars (2006) termed 'true integration'. Assimilation has occurred at the City Clubs as despite integrative capacity being achieved members of the non-dominant group (the disability football club) have forgone their cultural identity to belong to the dominant group (mainstream 
club). Extending the concerns of Hums et al. (2003) and Atherton et al. (2001) to this case, the risks inherent in assimilation could lead to a loss of the disability football club's and player's identity within this new club. Accommodation has occurred at Town United as while the mainstream club speaks positively about the merger, the disability section's staff have perspectives that differ dramatically and potentially harm the efforts to create a more integrated club. As Howe (2007) cautions, this withdrawal could end up making the disability section's perceived secondary status a reality.

By drawing on our theoretical framework of Hall et al. (2003) and Berry (1997) these findings add a managerial/resource perspective to the body of international research that investigates the process of vertical integration in disability sport. Our exploratory, qualitative approach has allowed us to fill in some of the gaps left by Wicker and Breuer (2014). We can see the programmes offered and as such developed a different, yet smaller-scale understanding of how integrative capacity was acquired or developed within each club.

We suggest that the development of an organisation's brand can be important for managing human resources, facilitating relationships with other organisations, and possibly lessening the obstacles in forming these inter-organisational partnerships. The above findings suggest that each club encountered a range of challenges similar to those experienced by other non-profit organisations in other national contexts (Hall et al., 2003; Misener \& Doherty, 2009; Sharpe, 2006; Wicker \& Breuer, 2014). That said, this research adds but a small piece to the complex jigsaw of how the dimensions of organisational capacity affect the ability of CSOs to achieve their missions.

Based on our findings, we offer the following recommendations for policy makers and sport practitioners. First, although our focus in this study was on football, there was nothing to indicate that it was the culture of the sport that facilitated or constrained the 
vertical integration process. We argue that all sports clubs should work towards an integrated, strategic and defined vision for integrating disability sport. Second, by combining Berry's framework with Howe's (2007) accommodation, there are five possible strategic outcomes that can occur because of the vertical integration process. To avoid assumptions that vertical integration will always lead to more inclusive organisations, all stakeholders should be briefed on this array of possibilities prior to any merger occurring. It falls to policy makers and NGB managers to initiative these discussions through stakeholder consultation. Related to this, mainstream clubs and disability clubs must establish open lines of communication during this consultation period. Conversations about each organisations' values and orientation should be as important as outlining how the mergers would take place. This will benefit the maintenance of internal relationships following the merger.

Finally, as endeavours to achieve integrative capacity do not always lead to the desired state of integration, policy makers need to provide support to implementers to improve specific dimensions of organisational capacity. While increased funding will support financial capacity, training programmes and grants are required to target human and structural capacity dimensions. For example, in this research Town United was able to increase the number of its personnel qualified in coaching disability football with the help of grants. While in this case the results of this support are still developing, it quickly boosted the club's human resource capacity. In broader terms, policy makers' familiarity with integrative capacity and how it can be supported could relieve some of the pressures placed on many sporting clubs, within football and across the sport industry in managing the many social policy expectations placed upon them.

As with most research there were limitations with our exploratory approach. The primary limitation for a study on disability sport is the lack of disabled voices in the data 
(Misener \& Darcy, 2014). Indeed, these findings would have been further enhanced if we had managed to gather a broader range of experiences from stakeholders at all of the ICP clubs including those that play football the other two clubs involved in these mergers. Although our methodology limits our ability to generalise we suggest that many CSOs in this region and further afield would experience these limited capacity issues. As such, the mix of clubs chosen in this current study provide a suitable sample. Informed by these findings, further research needs to understand the longer-term outcomes from the vertical integration process, from not just multiple geographic regions, but from multiple levels of analysis and involving a wider set of stakeholders. 


\section{References}

Allison, M. (2001). Sports clubs in Scotland. Edinburgh, Scotland: Sport Scotland.

Atherton, M., Russell, D. \& Turner, G. H. (2001). More than a match: The role of football in Britain's deaf community. Soccer and Society 2(3), 22-43.

Barr, O. (2011). What is 'mainstream'? Journal of Intellectual Disabilities, 15(3), 155156.

Berry, J. W. (1997). Immigration, acculturation and adaption. Applied Psychology,46, $5-34$.

Braun, V. Clarke, V., \& Weate, P. (2016). Using thematic analysis in sport and exercise research. In B. Smith and A.C. Sparkes (Eds). Routledge handbook of qualitative research in sport and exercise (pp. 191-205). Oxon: Routledge.

Brittain, I. (2004). Perceptions of disability and their impact upon Involvement in sport for people with disabilities at all levels. Journal for Sport and Social Issues, 28(4), 429-452.

Bouttet, F. (2016). Inclusion as a norm. Multi-scalar influences on the recognition of people with disabilities in French national sports organisations. Loisir et Société / Society and Leisure, 39(2),.274-289.

Chappelet, J.L. (2011). Strategic management and planning. In L. Robinson and D. Palmer (Eds.). Managing voluntary sport organisations (pp. 51-69). Oxon: Routledge.

Clark, B. \& Mesch, J. (2018) A global perspective on disparity of gender and disability for deaf female athletes. Sport in Society, (21)1, 64-75.

Collins, M., \& Kay, T. (2003). Sport and social exclusion. Oxon: Routledge. 
Cordery, C.J., Sim, D., Baskerville, R.F. (2013). Three models, one goal: Assessing financial vulnerability in New Zealand amateur sports clubs. Sport Management Review, 16, 186-199.

Crawford, J. L., \& Stodolska, M. (2009). Constraints experienced by elite athletes with disabilities in Kenya, with implications for the development of a new hierarchical model of constraints at the societal level. Journal of Leisure Research, 40(1), 128-156.

Cunningham, G. (2016). Diversity and inclusion in sports organisations, $3^{\text {rd }}$ edition. Oxon: Routledge.

Darcy, S., \& Dowse, L. (2012). In search of a level playing field - the constraints and benefits of sport participation for people with intellectual disability. Disability \& Society, 28(3), 393-497.

Darcy, S. Lock, D., \& Taylor, T. (2017). Enabling inclusive sport participation: effects of disability and support needs on constraints to sport participation. Leisure Sciences, 39(1), 20-41.

Doherty, A. Misener, K., \& Cuskelly, G., (2014). Toward a multidimensional framework of capacity in community sport clubs. Nonprofit and Voluntary Sector Quarterly, 43(2), 124S-142S.

Elling, A., De Knop, P., \& Knoppers, A. (2001). The social integrative meaning of sport: a critical and comparative analysis of policy and practice in the Netherlands. Sociology of Sport Journal, 18, 414-434.

European Commission (2007). White Paper on Sport. European Commission. Accessed $23^{\text {rd }}$ February 2018 at https://eur-lex.europa.eu/legalcontent/EN/TXT/?uri=CELEX\%3A52007DC0391 
Fitzgerald, H. (2012). 'Drawing' on disabled students' experiences of physical education and stakeholder responses. Sport, Education and Society, 17(4), 443-462.

French, D., \& Hainsworth, J. (2001). 'There aren't any buses and the swimming pool is always cold!': Obstacles and opportunities in the provision of sport for disabled people. Managing Leisure, 6(1), 35-49.

Hall, M. H., Andrukow, A., Barr, C., Brock, K., de Wit, M., Embuldeniya, D., Jolin, L., Lasby, D., Malinsky, E., Stowe, S., \& Vallaincourt, Y. (2003). The capacity to serve: A qualitative study of the challenges facing Canada's nonprofit and voluntary organisations. Toronto, Ontario, Canada: Canadian Centre for Philanthropy.

Hennink, M., Hutter, I., \& Bailey, A. (2015). Qualitative research methods. London: SAGE.

Howe, P. D. (2007). Integration of Paralympic athletes into athletics Canada. International Journal of Canadian Studies/Revue internationale d'études canadiennes, (35),133-149.

Hudson, N.A., Mrozik, J.H. White, R., Northend, K., Moore, S., Lister, K. \& Rayner, K. (2017). Community football teams for people with intellectual disabilities in secure settings: "They take you off the ward, it was like a nice day, and then you get medals at the end ”. Journal of Applied Research in Intellectual Disabilities, 31, 213-225.

Hughes, B., \& Patterson, K. (1997). The social model of disability and the disappearing body: Towards a sociology of impairment. Disability \& Society, 12, 325-340.

Hums, M.A., Moorman, A.M. and Wolff, E.A. (2003). The inclusion of the Paralympics in the Olympic and amateur sports act: Legal and policy implications for 
integration of athletes with disabilities into the United States Olympic Committee and national governing bodies Journal of Sport and Social Issues 27(3), 261-275.

Hylton, K. (2013). Sport and social integration. In B. Houlihan and M. Green (Eds). Routledge Handbook of Sports Development (pp 100-113). Oxon: Routledge. Irish Football Association (2016). IFA Disability Football Strategic Plan (2016-2020). Belfast: IFA, pp.1-12.

Jeanes. R., Spaaij, R., Magee, J., Farquharson, K., Gorman, S., \& Lusher, D. (2018). 'Yes we are inclusive': Examining provision for young people with disabilities in community sport clubs. Sport Management Review, (21)1, 38-50.

Jones, D. B. (2003). "Denied from a lot of places" barriers to participation in community recreation programs: Perspectives of parents. Leisure/Loisr, 28(12), 49-69.

Kitchin, P. J. and Howe, P. D. (2014). The mainstreaming of disability cricket in England and Wales: Integration 'One game' at a time. Sport Management Review, 17(1), 65-77.

Macbeth, J. (2008). Equality issues within partially sighted football in England. In C. Hallinan \& S. Jackson (Eds.), Social and cultural diversity in a sporting world (pp. 65-80). Bingley: Emerald.

Macbeth, J. L. (2009) Restrictions of activity in partially sighted football: experiences of grassroots players. Leisure Studies, 28(4), 455-467.

Macbeth , J. \& Magee, J. (2006) 'Captain England? Maybe one day I will': Career paths of elite partially sighted footballers. Sport in Society, 9(3), 444-462.

McConkey, R., Dowling, S., \& Hassan, D. (2014). Sport, coaching and intellectual disability. Oxon: Routledge. 
Misener, K., \& Doherty, A. (2009). A case study of organisational capacity in nonprofit community sport. Journal of Sport Management, 23(4), 457-482.

Misener, L., \& Darcy, S. (2014). Managing disability sport: From athletes with disabilities to inclusive organisational perspectives. Sport Management Review, $17,1-7$

Oliver, M., \& Barnes, C. (2012). The new politics of disablement. Hampshire: Palgrave Macmillan.

Paramio-Salcines, J.L., \& Kitchin, P.J. (2013). Institutional perspectives on the implementation of disability legislation and services for spectators with disabilities in European professional football. Sport Management Review, 16, $365-377$.

Piso, Z., O’Rouke, M., \& Weathers, K.C. (2016). Out of the fog: Catalysing integrative capacity in interdisciplinary research. Studies in History and Philosophy of Science, 56, 84-94.

Ruffié, S., Ferez, E., \& Lantz, E. (2014). From the institutionalisation of 'All Disabilities' to comprehensive sports integration: France joining the Paralympic movement (1954-2012). The International Journal of the History of Sport, 31(17), 2245-2265.

Salazar, M.R., Lant, T.K., Fiore, S.M. \& Salas, E. (2012). Facilitating innovation in diverse science teams through integrative capacity. Small Group Research, 43, $527-558$.

Scope (2018). The social model of disability. What is it and why is it important. Accessed on $4^{\text {th }}$ January 2018 at https://www.scope.org.uk/about-us/ourbrand/social-model-of-disability

Shakespeare, N. (2006). Disability rights and wrongs. Oxon: Routledge 
Sharpe, E. (2006). Resources at the grassroots of recreation: Organisational capacity and quality of experience in a community sport organisation. Leisure Sciences, 28(4), 385-401.

Smith, B., \& Bundon, A. (2018). Disability models: Explaining and understanding disability sport in different ways. In I. Brittain and A. Beacom (Eds.). The Palgrave Handbook of Paralympic Studies (pp. 15-34). Basingstoke: Palgrave.

Sørensen, M., \& Khars, N. (2006). Integration of disability sport in the Norwegian sport organisations: Lessons learned. Adapted Physical Activity Quarterly, 23(2), 184-202.

Sotiriadou, P., \& Wicker, P. (2014). Examining the participation patterns of an ageing population with disabilities in Australia. Sport Management Review, 17(1), 3548.

Stewart, D. (1993). Deaf Sports: The Impact of Sports within the Deaf Community. Washington: Gallaudet University Press.

Stride, A. \& Fitzgerald, H. F. (2011). Girls with learning disabilities and 'football on the brain'. Soccer \& Society, 12(3), 457-470.

Swierzy, P., Wicker, P., \& Breuer, C. (2018). The impact of organisational capacity on voluntary engagement in sport clubs: A multi-level analysis. Sport Management Review, 21(3), 307-320.

Terzi, L. (2004) The social model of disability: A philosophical critique. Journal of Applied Philosophy, 21(2), 141-157.

Thibault, L. Frisby, W. \& Kikulis, L. (1999). Interorganisational linkages in the delivery of local leisure services in Canada: Responding to economic, political and social pressures. Managing Leisure, 4(3), 125-151. 
Thibault, L., \& Harvey, (1997). Fostering interorganisational linkages in the Canadian sport delivery system. Journal of Sport Management, 11(1), 45-68.

Thomas, N., \& Smith, A. (2009). Disability, sport and society: An introduction. Oxon: Routledge.

Townsend, R.C., Smith, B. and Cushion, C. (2015). Disability sports coaching: Towards a critical understanding. Sports Coaching Review, 4, 80-98.

Valet, A. (2018). About inclusive participation in sport: Cultural desirability and technical obstacles. Sport in Society, 21(1), 137-151.

Vail, S. (2007). Community development and sport participation. Journal of Sport Management, 21(4), 571-596

Wicker, P., \& Breuer, C. (2013). Understanding the importance of organisational resources to explain organisational problems: Evidence from non-profit sport clubs in Germany. Voluntas, 24(2), 461-484.

Wicker, P., Feiler, S., \& Breuer, C. (2013). Organizational mission and revenue diversification among non-profit sports clubs. International Journal of Financial Studies, 1, 119-136.

Wicker, P., \& Breuer, C. (2014). Exploring the organisational capacity and organisational problems of disability sport clubs in Germany using matched pairs analysis. Sport Management Review, 17(1), 23-34. 